\title{
PENGARUH MEDIA PEMBELAJARAN LCD PROYEKTOR DAN MINAT BELAJAR DENGAN HASIL BELAJAR MATA PELAJARAN KESELAMATAN DAN KESEHATAN KERJA (K3) SISWA KELAS X TEKNIK GAMBAR BANGUNAN SMK NEGERI 4 SUKOHARJO Adil Tanendha ${ }^{1}$, Sutrisno ${ }^{2}$, Agus Efendi ${ }^{3}$
}

\begin{abstract}
ABSTRAK
Tujuan dari penelitian ini adalah: 1) Untuk mengetahui pengaruh antara media pembelajaran LCD (Liquid Crystal Display) proyektor dengan hasil belajar pada mata pelajaran keselamatan dan kesehatan kerja siswa kelas X teknik gambar bangunan SMK Negeri 4 Sukoharjo. 2) Untuk mengetahui pengaruh antara minat belajar dengan hasil belajar pada mata pelajaran keselamatan dan kesehatan kerja siswa kelas $\mathrm{X}$ teknik gambar bangunan SMK Negeri 4 Sukoharjo. 3) Untuk mengetahui pengaruh antara media pembelajaran LCD proyektor dan minat belajar dengan hasil belajar mata pelajaran keselamatan dan kesehatan kerja siswa kelas X teknik gambar bangunan SMK Negeri 4 Sukoharjo.

Populasi dalam penelitian ini adalah seluruh siswa kelas $X$ teknik gambar bangunan SMK Negeri 4 Sukoharjo. Sampel diambil sebanyak 71 siswa dengan teknik random sampling. Data yang diperlukan diperoleh melalui angket, tes dan dokumentasi. Angket dan tes sebelumnya diuji cobakan terhadap 34 siswa lalu diuji validitas Karl Pearson, dan uji reliabilitas Cronbach's Alpha untuk angket, untuk tes ditambah dengan uji kesukaran, dan uji daya pembeda. Teknik analisis data yang digunakan adalah teknik analisis regresi ganda.

Kesimpulan dalam penelitian ini adalah: 1) Ada pengaruh yang positif media pembelajaran LCD proyektor dengan hasil belajar pada mata pelajaran keselamatan dan kesehatan kerja siswa kelas $\mathrm{X}$ teknik gambar bangunan SMK Negeri 4 Sukoharjo dengan sumbangan relatif 17,468\% dan sumbangan efektif $3,84 \%$. 2) Ada pengaruh yang positif antara minat belajar dengan hasil belajar pada mata pelajaran keselamatan dan kesehatan kerja siswa kelas X teknik gambar bangunan SMK Negeri 4 Sukoharjo dengan sumbangan relatif 82,621\% dan sumbangan efektif $18,17 \%$. 3) Ada pengaruh yang positif antara media pembelajaran LCD proyektor dan minat belajar dengan hasil belajar mata pelajaran keselamatan dan kesehatan kerja siswa kelas $X$ teknik gambar bangunan SMK Negeri 4 Sukoharjo dengan besarnya pengaruh media pembelajaran LCD proyektor dan minat belajar sebesar $22,0 \%$.
\end{abstract}

Kata Kunci: Media Pembelajaran LCD Proyektor, Minat Belajar, Hasil Belajar

1 Pendidikan Teknik Bangunan Universitas Sebelas Maret

2,3 Dosen Pendidikan Teknik Bangunan Universitas Sebelas Maret 


\title{
THE INFLUENCE BETWEEN LEARNING MEDIA BY LCD PROJECTOR AND INTEREST IN LEARNING WITH THE RESULT OF LEARNING ON THE SUBJECTS OF OCCUPATIONAL SAFETY AND HEALTH (OSH) GRADE X ARCHITECTURE ENGINEERING STUDENT OF SMK NEGERI 4 SUKOHARJO Adil Tanendha ${ }^{1}$, Sutrisno $^{2}$, Agus Efendi ${ }^{3}$
}

\begin{abstract}
The purpose of this research are: 1) To determine the influence between learning media by LCD (Liquid Crystal Display) projector with the result of learning on the subjects of occupational safety and health grade $\mathrm{X}$ architecture engineering student of SMK Negeri 4 Sukoharjo. 2) To determine the influence between interest in learning with the result of learning on the subjects of occupational safety and health grade $X$ architecture engineering student of SMK Negeri 4 Sukoharjo. 3) To determine the influence between learning media by LCD projector and interest in learning with the results of learning on the subjects occupational safety and health grade $X$ architecture engineering student of SMK Negeri 4 Sukoharjo.

The population in this research were all students of grade $\mathrm{X}$ architecture engineering SMK Negeri 4 Sukoharjo. Samples taken as many as 71 students using random sampling technique. Data obtained through the questionnaire, test and documentation. Questionnaires and tests previously been tested against 34 students and then being tested the validity by Karl Pearson, and using reliability test with Cronbach's Alpha for the questionnaire, whereas for the test being added with the difficulty test, and distinguishing test. Data analysis technique used is the multiple regression analysis.

The conclusion of this study were: 1) There is a positive influence between learning media by LCD projector with the result of learning on the subjects of occupational safety and health grade $\mathrm{X}$ architecture engineering student of SMK Negeri 4 Sukoharjo with the 17,468\% relative contribution and the 3,84\% effective contribution. 2) There is a positive influence between interest in learning with the result of learning on the subjects of occupational safety and health grade $X$ architecture engineering student of SMK Negeri 4 Sukoharjo with the 82,621\% relative contribution and the $18,17 \%$ effective contribution. 3 ) There is a positive influence between learning media by LCD projector and interest in learning with the results of study subjects occupational safety and health grade $X$ architecture engineering student of SMK Negeri 4 Sukoharjo with the influence of media learning by LCD projector and interest in learning is $22,0 \%$.
\end{abstract}

Keywords: Learning Media by LCD Projector, Interest in Learning, The Result of Learning

1 Vocational Technical Education, Sebelas Maret University

2,3 Leaturer Vocational Technical Education, Sebelas Maret University 


\section{PENDAHULUAN}

Dalam proses pendidikan yang dilaksanakan di sekolah memerlukan tenaga pendidik yang berkualitas serta dengan didukung adanya media pembelajaran yang memadai untuk mewujudkan masyarakat madani yang mampu menguasai, mengembangkan, mengendalikan dan memanfaatkan teknologi. Dalam kegiatan tersebut media pembelajaran memiliki peranan penting dalam mendukung terjadinya proses belajar mengajar. Maka tidaklah mengherankan jika banyak sekolah melakukan pengadaan dan penggunaan media pembelajaran dalam kegiatan pembelajaran.

Dalam perkembangan teknologi yang semakin pesat maka media pembelajaran pun turut mengalami perkembangan pula. Salah satu media pembelajaran yang sedang popular saat ini adalah LCD (Liquid Crystal Display) Proyektor. Media pembelajaran LCD dapat membantu guru dalam menyampaikan materi pelajaran dan menyajikan pelajaran yang dapat mendukung aktivitas belajar siswa terhadap materi secara optimal dan memberikan gairah dalam belajar agar dapat merangsang proses belajar mengajar yang berlangsung secara efektif dan efisien. Sebab dalam proses belajar mengajar kriteria yang berhasil di tandai dengan terjadinya perubahan tingkah laku pada diri individu yang belajar. Mengingat pentingnya penggunaan media pembelajaran pada setiap proses belajar mengajar, maka menarik untuk diteliti dan untuk mengetahui dampak penggunaan media LCD di atas terhadap hasil belajar khususnya.

Selain media pembelajaran, hal yang mempengaruhi hasil belajar adalah minat belajar siswa itu sendiri. Karena minat belajar merupakan suatu dorongan yang menggerakkan siswa untuk mau mengikuti proses pembelajaran atau tidak. Minat belajar seorang siswa dipengaruhi oleh beberapa faktor salah satunya adalah media pembelajaran, semakin menarik media pembelajaran yang diberikan oleh guru dalam proses pembelajaran maka minat siswa dalam belajar dapat meningkat.

Berdasarkan observasi awal yang telah dilakukan oleh peneliti, di SMK Negeri 4 Sukoharjo sudah memiliki fasilitas pembelajaran yang cukup lengkap. Mulai dari tersedianya laboratorium, ruang praktik, perpustakan dan media pembelajaran LCD Proyektor. Akan tetapi untuk media pembelajaran LCD Proyektor masih belum tersedia di masing-masing ruang kelas, misalnya untuk jurusan teknik gambar bangunan tersedia beberapa LCD Proyektor untuk semua kelas yang masing-masing harus bergantian menggunakannya. Hal ini yang mendasari peneliti mengangkat tema media pembelajaran LCD proyektor yang digunakan di SMK Negeri 4 Sukoharjo.

Mata pelajaran Keselamatan dan Kesehatan Kerja (K3) merupakan salah satu mata pelajaran yang cukup sulit, karena mencakup banyak materi dan perlu banyak hafalan mengenai konsep keselamatan dan kesehatan kerja yang baik. Berdasarkan observasi peneliti para siswa mengalami kesulitan dalam proses 
memahami materi dikarenakan banyak siswa yang tidak konsentrasi pada pelajaran yang disampaikan oleh guru, dan banyak siswa yang justru bermain game, serta siswa asyik mengobrol sendiri dengan teman sebangkunya.

Untuk itu guru memerlukan inovasi khusus yang dapat meningkatkan minat belajar siswa dan membuat proses pembelajaran yang menarik. Salah satu caranya dalah dengan menggunakan media pembelajaran LCD Proyektor.

Menurut Rahardjo (1984: 48) media pembelajaran merupakan wadah dari pesan yang oleh sumber atau penyalurnya ingin diteruskan kepada sasaran atau penerima pesan tersebut, adapun pesan yang ingin disampaikan adalah pesan pembelajaran dengan tujuan terjadinya proses belajar. Menurut Hamdani (2011: 90) secara singkat menyatakan media pembelajaran adalah alat yang digunakan dalam proses belajar mengajar. Dari kedua pendapat tersebut sama-sama menyebutkan bahwa yang dimaksud media pembelajaran merupakan sebuah wadah atau alat yang digunakan dalam proses pembelajaran.

LCD adalah suatu jenis media tampilan yang menggunakan kristal cair sebagai penampil utama. LCD sudah digunakan di berbagai bidang misalnya dalam alat-alat elektronik seperti televisi, kalkulator ataupun layar komputer. Pada prinsipnya proyektor LCD sama dalam bentuk perangkat elektroniknya dengan komputer biasa, perbedaannya hanya pada monitor (display) saja. Alat ini dapat digunakan dalam ruangan untuk menampilkan program yang diperlukan. Keuntungan dari proyektor LCD ini adalah layar pada monitor dapat ditampilkan kedalam bentuk gambar atau layar yang lebih besar seperti proyektor pada umumnya.

Menurut W.S Winkel (2004: 188) "Minat belajar adalah kecenderungan subyek yang menetap untuk merasa tertarik pada bidang studi atau pokok bahasan tertentu dan merasa senang mempelajari materi itu". Menurut Slameto (2003: 180), "Minat belajar adalah suatu rasa lebih suka dan rasa ketertarikan belajar pada suatu hal atau aktifitas, tanpa ada yang menyuruh".

Hasil belajar merupakan suatu bentuk penilaian dari proses pembelajaran yang telah dilakukan. Menurut Slameto (2003: 2), "Belajar ialah suatu proses usaha yang dilakukan seseorang untuk memperoleh suatu perubahan tingkah laku yang baru secara keseluruhan, sebagai hasil pengalamannya sendiri dalam interaksi dengan lingkungannya.", Menurut Nana (2005: 22), "Hasil belajar adalah kemampuan-kemampuan yang dimiliki siswa setelah ia menerima pengalaman belajarnya."

Berdasarkan latar belakang dan kajian teori yang telah dipaparkan sebelumnya, maka tujuan dari penelitian ini adalah untuk mengetahui: (1) Pengaruh yang positif antara Media Pembelajaran LCD Proyektor dengan Hasil Belajar Mata Pelajaran Keselamatan dan Kesehatan Kerja (K3) Siswa Kelas X Teknik Gambar Bangunan SMK Negeri 4 Sukoharjo, (2) Pengaruh yang positif antara Minat Belajar siswa dengan Hasil Belajar Mata Pelajaran Keselamatan dan 
Kesehatan Kerja (K3) Siswa Kelas X Teknik Gambar Bangunan SMK Negeri 4 Sukoharjo, (3) Pengaruh yang positif antara Media Pembelajaran LCD Proyektor dan Minat Belajar siswa dengan Hasil Belajar Mata Pelajaran Keselamatan dan Kesehatan Kerja (K3) Siswa Kelas X Teknik Gambar Bangunan SMK Negeri 4 Sukoharjo.

\section{METODE PENELITIAN}

Penelitian dilaksanakan di SMK Negeri 4 Sukoharjo. Waktu penelitian mencakup rangkaian dari kegiatan dan alokasi waktu yang dibutuhkan peneliti dalam melakukan penelitian. Penelitian ini dilaksanakan selama tujuh bulan, terhitung dari persiapan penyusunan proposal penelitian sampai dengan laporan penelitian selesai disusun, yaitu dari bulan Desember 2015 sampai dengan Juni 2016.

Penelitian ini merupakan jenis penelitian deskriptif kuantitatif. Bila ditinjau berdasarkan klasifikasi, penelitian ini termasuk dalam description research, yaitu penelitian ini memusatkan perhatian pada masalah-masalah aktual yang terjadi pada saat penelitian ini dilakukan.

Populasi dalam penelitian ini adalah seluruh siswa kelas $\mathrm{X}$ Teknik Gambar Bangunan SMK Negeri 4 Sukoharjo. Dalam penelitian ini, teknik sampling yang digunakan adalah Simple Random Sampling. Dimana simple random sampling yang digunakan berjumlah 71 siswa yang dijadikan sampel terdiri dari kelas X-TGB A dan X TGB B. Kemudian untuk kelas uji coba instrument yaitu kelas X - TGB $C$ yang berjumlah 34 siswa.

Teknik pengumpulan data dalam penelitian ini menggunakan (1) angket, (2) tes dan (3) dokumentasi. Teknik analisis data yang digunakan dalam penelitian ini adalah regresi ganda.

Untuk angket dan tes sebelum di analisis data harus di uji validitas instrumennya terlebih dahulu. Uji validitas instrumen angket dan tes dilakukan di kelas $\mathrm{X}$ TGB C yang berjumlah 34 siswa. Uji prasyarat yang digunakan untuk angket adalah uji validitas Karl Pearson, dan uji reliabilitas Crobbach's Alha. Untuk tes, uji prasyaratnya ditambah dengan uji kesukaran, dan uji daya pembeda.

Berdasarkan hasil analisis, uji coba angket dan soal dilakukan kepada 34 siswa kelas X-TGB C yang dijadikan sebagai sampel uji coba. Pada teknik pengambilan data melalui angket, validasi instrumen menggunakan uji validitas dan uji reliabilitas. Pada angket media pembelajaran LCD proyektor terdapat 20 item pertanyaan, setelah dianalisis terdapat 16 item pertanyaan yang valid dan terdapat 4 item pertanyaan yang tidak valid dengan tingkat reliabilitas Sangat Tinggi.

Adapun pada angket minat belajar terdapat 20 item pertanyaan, hasil analisis menunjukkan terdapat 15 item pertanyaan yang valid dan terdapat 5 item pertanyaan yang tidak valid dengan tingkat reliabilitas Sangat Tinggi.

Pada teknik pengambilan data melalui soal, validasi instrumen menggunakan uji validitas, uji reliabilitas, uji tingkat kesukaran dan 
uji daya pembeda. Untuk soal (dalam hal ini dipilih materi pemilihan alatalat dan perlengkapan K3) terdapat 20 item soal pilihan ganda. hasil analisis menunjukkan terdapat 14 item soal yang valid dan terdapat 5 item soal yang tidak valid.

Dari seluruh data tersebut dapat dinyatakan bahwa seluruh item angket dan soal yang diujikan memenuhi syarat untuk dijadikan sebagai instrumen penelitian. Analisis hasil uji coba angket dan soal menggunakan bantuan program SPSS for windows 17.0.

Setelah dilakukan uji coba instrumen, hanya instrumen yang valid lah yang digunakan sebagai bahan analisis data. Data ini kemudian dilakukan uji validitas instrumen lalu data diolah uji normalitas, uji linieritas sebagai syarat untuk melakukan pengujian hipotesis.

Setelah dilakukan analisis uji prasyarat kemudian data masuk kedalam pengujian hipotesis, dalam pengujian hipotesis ini menggunakan teknik analisis regresi ganda. Setelah dihitung analisis regresinya kemudian menghitung besarnya sumbangan relatif dan sumbangan efektif dari masing-masing variable guna menunjukkan variable mana yang berpengaruh lebih dominan terhadap hasil belajar.

\section{ANALISIS DATA DAN PEMBAHASAN}

Data Media LCD Proyektor diperoleh dengan teknik angket. Dari hasil analisis dan perhitungan diperoleh nilai tertinggi sebesar 64 , nilai terendah sebesar 38, rerata sebesar 49,39, nilai tengah sebesar
48, nilai yang paling sering muncul sebesar 47, simpangan baku sebesar 5,528, dan varian sebesar 27,642. Untuk melihat apakah data yang diperoleh berdistribusi normal atau tidak, maka disajikan histogram dari distribusi frekuensi data media LCD proyektor sebagai berikut:

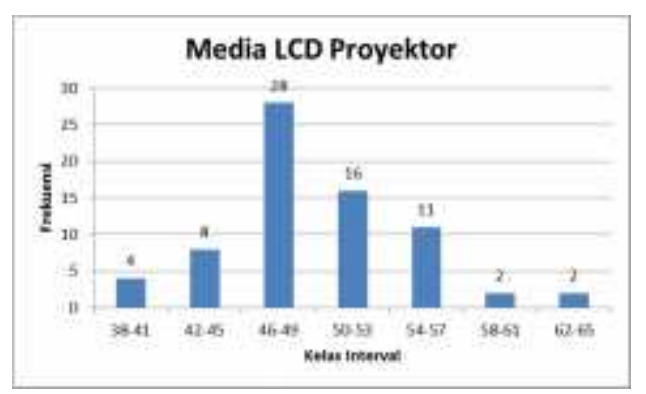

Gambar 4.1. Histogram Data Media LCD Proyektor

Data minat belajar diperoleh dengan teknik angket. Dari hasil analisis dan perhitungan diperoleh nilai tertinggi sebesar 57, nilai terendah sebesar 33, rerata sebesar 43,73 , nilai tengah sebesar 44 , nilai yang paling sering muncul sebesar 44, simpangan baku sebesar 4,687, dan varian sebesar 21,970. Untuk melihat apakah data yang diperoleh berdistribusi normal atau tidak, maka disajikan histogram dari distribusi frekuensi data minat belajar sebagai berikut:

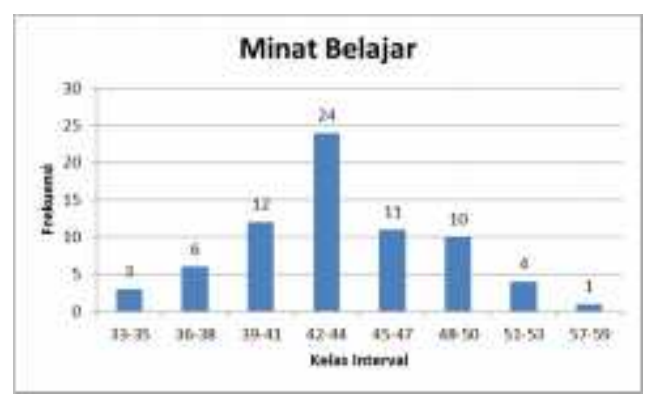

Gambar 4.2. Histogram Data Minat Belajar 
Data hasil belajar pada mata pelajaran keselamatan dan kesehatan kerja (K3) diperoleh dengan teknik soal/tes, yaitu dengan menggunakan soal mata pelajaran keselamatan dan kesehatan kerja (K3) ada kompetensi pemilihan alat-alat dan perlengkapan K3. Dari hasil analisis dan perhitungan diperoleh nilai tertinggi sebesar 100, nilai terendah sebesar 43 , rerata sebesar 76,62 , nilai tengah sebesar 78,50, nilai yang paling sering muncul sebesar 71, simpangan baku sebesar 12,780, dan varian sebesar 163,326. Untuk melihat apakah data yang diperoleh berdistribusi normal atau tidak, maka disajikan histogram dari distribusi frekuensi data hasil belajar sebagai berikut:

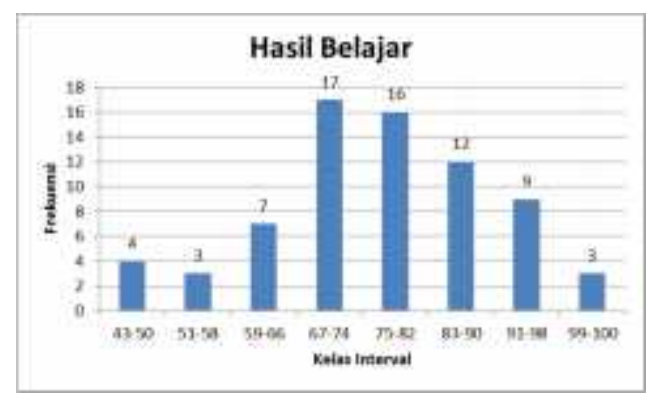

Gambar 4.3. Histogram Data Hasil Belajar Pada Mata Pelajaran Keselamatan Dan Kesehatan Kerja (K3)

Setelah dilakukan deskripsi data dari masing-masing variabel. kemudian dilakukan uji prasyarat untuk masing-masing variabelnya. Uji prasyarat yang dilakukan adalah uji normalitas dan uji liniearitas.

Tujuan uji normalitas adalah untuk mengetahui apakah data dari sampel penelitian berasal dari populasi yang berdistribusi normal atau tidak. Uji normalitas dilakukan menggunakan kolmogorov smirnov menggunakan program SPSS versi
17.0. Kriteria dari uji normalitas adalah data berdistribusi normal apabila mempunyai nilai signifikansi $>$ 0,05. Adapun ringkasan uji normalitas adalah sebagai berikut:

Tabel 4.4 Ringkasan Hasil Uji Normalitas

\begin{tabular}{cccc}
\hline & $\begin{array}{c}\text { Media } \\
\text { LCD } \\
\text { proyektor }\end{array}$ & $\begin{array}{c}\text { Minat } \\
\text { Belajar }\end{array}$ & $\begin{array}{c}\text { Hasil } \\
\text { Belajar }\end{array}$ \\
\hline $\begin{array}{c}\text { Signifi } \\
\text { kansi } \\
(\rho)\end{array}$ & 0,117 & 0,345 & 0,103 \\
\hline
\end{tabular}

Tujuan uji linearitas adalah untuk mengetahui bagaimana bentuk pengaruh antara satu variabel bebas dengan satu variabel terikat. Adapun ringkasan hasil uji linearitas dan keberartian regresi linear yang dilakukan menggunakan alat bantu program SPSS versi 17.0 adalah sebagai berikut:

Tabel 4.5. Ringkasan Hasil Uji Linearitas

\begin{tabular}{|c|c|c|c|c|}
\hline $\begin{array}{c}\text { Variabel } \\
\text { yang } \\
\text { diukur }\end{array}$ & \multicolumn{2}{|c|}{ Harga $\mathrm{F}$} & $\begin{array}{c}\text { Sig } \\
(\rho)\end{array}$ & $\begin{array}{c}\text { Kesim } \\
\text { pulan }\end{array}$ \\
\cline { 2 - 5 } $\mathrm{F}_{\text {hitung }}$ & $\mathrm{F}_{\text {tabel }}$ & & \\
\hline $\mathrm{X}_{1} \mathrm{Y}$ & 1,139 & $\begin{array}{c}\mathrm{F}_{0,05}= \\
2,00\end{array}$ & $\begin{array}{c}0,34 \\
5\end{array}$ & Linier \\
& & & & \\
$\mathrm{X}_{2} \mathrm{Y}$ & 1,598 & $\begin{array}{c}\mathrm{F}_{0,05}= \\
2,00\end{array}$ & 0,06 & Linier \\
& & & & \\
\hline
\end{tabular}

Berdasarkan analisis uji prasyarat seluruh variabel normal dan linier, maka langkah selanjutnya adalah melakukan uji hipotesis yang ada menggunakan teknik analisis regresi ganda. 
Sebelum melakukan pengujian hipotesis penelitian terlebih dahulu dilakukan analisis regresi linear berganda. Adapun ringkasan analisis regresi linear berganda yang dilakukan dengan alat bantu program SPSS versi 17.0 adalah:

Tabel 4.6 Ringkasan Hasil Uji Regresi Linear Berganda

\begin{tabular}{llll}
\hline Variabel & $\begin{array}{l}\text { Koefisien } \\
\text { Regresi }\end{array}$ & $\mathrm{T}$ & Sig \\
& 69,313 & 30,852 & 0,00 \\
Media & 0,211 & 4,693 & 0,00 \\
$\begin{array}{l}\text { LCD } \\
\text { Proyektor }\end{array}$ & & & \\
$\begin{array}{l}\text { Minat } \\
\text { Belajar }\end{array}$ & 0,405 & 4,188 & 0,00 \\
\hline $\mathrm{F}_{\text {hitung }}=$ & 17,776 & & \\
$\mathrm{R}^{2}=$ & 0,220 & & \\
\hline
\end{tabular}

Berdasarkan tabel 4.6 diperoleh persamaan regresi linear berganda sebagai berikut: $\mathrm{Y}=$ $69,313+0,211 \mathrm{X} 1+0,405 \mathrm{X} 2$

Adapun interpretasi dari persamaan regresi linear berganda tersebut adalah:

(a). $a=69,313$, menyatakan bahwa jika media LCD proyektor dan minat belajar tidak mengalami perubahan maka nilai hasil belajar pada mata pelajaran keselamatan dan kesehatan kerja (K3) sebesar 69,313.

(b). b1 = 0,211 menyatakan bahwa jika media LCD proyektor bertambah sebesar 1 poin, maka hasil belajar pada mata pelajaran keselamatan dan kesehatan kerja (K3) akan mengalami peningkatan sebesar 0,211. Dengan asumsi tidak ada penambahan (konstan) nilai minat belajar.

(c). b2 =0,405, menyatakan bahwa jika minat belajar bertambah sebesar 1 poin, maka hasil belajar pada mata pelajaran keselamatan dan kesehatan kerja (K3) akan mengalami peningkatan sebesar 0,405. Dengan asumsi tidak ada penambahan (konstan) nilai media LCD proyektor.

Setelah dilakukan analisis regresi ganda, hasil dari analisis ini kemudian diolah untuk mengetahui sumbangan relatife dan sumbangan efektif dari masing-masing variabel dan koefisien determinasi dari kedua variabel.

Dari hasil perhitungan diketahui bahwa variabel media pembelajaran LCD proyektor memberikan sumbangan relatif sebesar $17,468 \%$ dan sumbangan efektif $3,84 \%$. Variabel minat belajar memberikan sumbangan relatif sebesar $82,621 \%$ dan sumbangan efektif $\quad 18,17 \%$. Dengan membandingkan nilai sumbangan relatif dan efektif nampak bahwa variabel minat belajar memiliki pengaruh yang lebih dominan terhadap hasil belajar Mata Pelajaran Keselamatan dan Kesehatan Kerja (K3) dibandingkan variabel media pembelajaran LCD proyektor.

Kemudian berdasarkan analisis data menggunakan alat bantu program SPSS versi 17.0 diperoleh nilai koefisien determinasi $\left(\mathrm{R}^{2}\right)$ sebesar 0,220. Arti dari koefisien ini adalah bahwa pengaruh yang diberikan oleh kombinasi variabel Media Pembelajaran LCD Proyektor dan Minat Belajar dengan Hasil 
Belajar Mata Pelajaran Keselamatan dan Kesehatan Kerja (K3) Siswa Kelas X Teknik Gambar Bangunan SMK Negeri 4 Sukoharjo adalah sebesar 22,0\%, sisanya dipengaruhi oleh variabel lain.

\section{SIMPULAN}

Berdasarkan hasil analisis data dan pembahasan yang telah diuraikan, maka dapat diambil kesimpulan sebagai berikut : (1) Terdapat pengaruh yang positif antara Media Pembelajaran LCD Proyektor dengan Hasil Belajar Mata Pelajaran Keselamatan dan Kesehatan Kerja (K3) Siswa Kelas X Teknik Gambar Bangunan SMK Negeri 4 Sukoharjo. (2) Terdapat pengaruh yang positif antara Minat Belajar siswa dengan Hasil Belajar Mata Pelajaran Keselamatan dan Kesehatan Kerja (K3) Siswa Kelas X Teknik Gambar Bangunan SMK Negeri 4 Sukoharjo. (3) Terdapat pengaruh yang positif antara Media Pembelajaran LCD Proyektor dan Minat Belajar siswa dengan Hasil Belajar Mata Pelajaran Keselamatan dan Kesehatan Kerja (K3) Siswa Kelas X Teknik Gambar Bangunan SMK Negeri 4 Sukoharjo.

\section{SARAN}

Bagi Guru, guru hendaknya menguasai penggunaan media pembelajaran LCD Proyektor untuk membuat kegiatan pembelajaran menjadi lebih baik dan menarik. Guru hendaknya dapat membangun minat belajar siswa sehingga siswa lebih giat dan semangat dalam setiap proses pembelajaran.

Bagi Siswa, siswa hendaknya bisa turut meenguasai penggunaan media pembelajaran LCD proyektor guna membantu guru dalam penggunaan pada saat proses pembelajaran. Siswa hendaknya memiliki minat belajar yang tinggi dalam setiap proses pembelajaran sehingga hasil belajar dari siswa tersebut dapat meningkat.

Bagi Sekolah, pihak sekolah hendaknya melakukan pengadaan media pembelajaran LCD Proyektor secara berkala agar kebutuhan media pembelajaran yang ada dapat terpenuhi sehingga siswa lebih bersemangat dalam proses pembelajarannya. Lingkungan dan fasilitas sekolah sebaiknya mampu membangun minat belajar siswa agar semakin meningkat. 


\section{DAFTAR PUSTAKA}

Hamdani. (2011). Strategi Belajar Mengajar. Bandung: Pustaka Setia.

Pengertian Media Pembelajaran LCD Proyektor.

Tersedia di

http://manyhund.blogspot.co.i d/2012/06/makalah-mediaohp-dan-LCD.html diakses pada tanggal 09 Januari 2016, jam 02.58

Rahardjo, R. (1984). "Media Pembelajaran". Dalam Miarso, Yusufhadi dkk. 1984. Teknologi Komunikasi Pendidikan. Jakarta: Rajawali.

Slameto., (2003), Belajar dan Faktor-Faktor Yang Mempengaruhinya, Rineka Cipta, Jakarta

Sudjana, Nana. (2005). Dasar-dasar Proses Belajar Mengajar, Bandung: PT. Sinar Baru Algesindo.

Winkel, W.S. (2004). Bimbingan dan Konseling di Institusi Pendidikan, Jakarta:

Grasindo 